\title{
Regulación de la utilización del aspartato por los astrocitos durante la prelactancia
}

\author{
Jairo Alfonso Tovar-Franco ${ }^{1 *}$, Maria Juliana Salamanca Ortiz ${ }^{2}$, Ludis Morales ${ }^{1}$ y Cecilia Espíndola ${ }^{1}$. \\ ${ }^{1}$ Departamento de Nutrición y Bioquímica. \\ ${ }^{2}$ Departamento de Biología \\ Pontificia Universidad Javeriana. Cra. $7^{a}$ \# 43-82, Bogotá D.C., Colombia \\ * jatovar@javeriana.edu.co
}

Recibido: 19-10-2009; Aceptado: 09-02-2010

\begin{abstract}
Resumen
En el período perinatal se incrementa la concentración de N-acetil-L-aspartato (NAA) producido por las neuronas, este sustrato es absorbido por los astrocitos e hidrolizado vía aspartoacilasa II (ASPA; EC 3.5.1.15) en acetato y aspartato. Se postula que el aspartato podría colaborar en suplir los requerimientos metabólicos de los astrocitos durante la prelactancia. Objetivos. Evaluar la capacidad de los astrocitos para utilizar el aspartato como sustrato metabólico en condiciones fisiológicas perinatales y determinar si la utilización del aspartato puede ser modificada por variaciones en las concentraciones de glucosa (Glc), lactato (Lac) y N-acetil-L-aspartato (NAA) y si estas variaciones de concentración, pueden regular la actividad enzimática de la ASPA. Materiales y métodos. Se incubaron cultivos quiescentes de astrocitos neonatales de rata Wistar con L-aspartato $(0.5 \mathrm{mM})$ y L-[U- $\left.{ }^{14} \mathrm{C}\right]$-aspartato $(2 \mu \mathrm{Ci})$, para evaluar su capacidad para utilizarlo como sustrato oxidativo y lipogénico. Se determino el efecto de la variación de las concentraciones de Lac, Glc y NAA, en condiciones fisiológicas perinatales como de adulto, sobre la utilización del aspartato (método radiométrico) y sobre la actividad del ASPA (método espectrofotométrico). Resultados. Se demostró que los astrocitos están en capacidad de utilizar el aspartato 87 veces más como sustrato oxidativo que lipogénico. Conclusiones. La utilización del aspartato y su destino es afectado significativamente $(\mathrm{p}<0,05)$ por las concentraciones de Lac, Glc y NAA. ASPA tiene una alta actividad, siendo regulada por disponibilidad de lactato y por el incremento de la disponibilidad de glucosa.
\end{abstract}

Palabras clave: aspartato, aspartoacilasa, astrocitos, prelactancia

\begin{abstract}
Regulation of the use of aspartate by the astrocytes during the presuckling period. During the perinatal period the concentration of $\mathrm{N}$-acetyl-L-aspartate (NAA) produced by neurons increases. This substrate is absorbed by the astrocytes and hydrolyzed via aspartoacylase II (ASPA; EC 3.5.1.15) in acetate and aspartate. We propose that the aspartate may help in fulfilling the astrocyte metabolic requirements during the presuckling period. Objectives. To evaluate the astrocyte ability to use the aspartate as a metabolic substrate in perinatal physiological conditions, and to determine whether the aspartate utilization can be modified by changes in the concentration of glucose (Glc), lactate (LAC) and N-acetyl-L-aspartate (NAA) and whether these variations in concentration can regulate the enzymatic activity of the ASPA. Materials and methods. Quiescent cultures of neonatal astrocytes of Wistar rat were incubated with L-aspartate $(0.5 \mathrm{mM})$ and $\mathrm{L}-\left[\mathrm{U}-{ }^{14} \mathrm{C}\right]$-aspartate $(2 \mu \mathrm{Ci})$, to assess their ability to use them as oxidative and lipogenic substrates. The effect of varying concentrations of Lac, Glc and NAA on the use of aspartate (radiometry method) and the ASPA activity (spectrophotometry method) was evaluated in both presuckling and adult physiological conditions. Results. Astrocytes are able to use aspartate 87 times more as an oxidative substrate than a lipogenic substrate. Conclusions. The use of aspartate and its destiny are affected significantly $(\mathrm{p}<0.05)$ by the concentrations of Lac, Glc and NAA. ASPA has a high activity being regulated by lactate availability and the increased availability of glucose.
\end{abstract}

Key words: aspartate, aspartoacylase, astrocytes, presuckling 


\begin{abstract}
Resumo
Regulação da utilização do aspartato pelos astrócitos durante a prelactância. No período perinatal aumenta a concentração de Nacetil-L-aspartato (NAA) produzido pelos neurônios, este substrato é absorvido pelos astrócitos e hidrolisado por via aspartoacilasa II (ASPA, EC 3.5.1.15) em acetato e aspartato. Postula-se que o aspartato poderia ajudar no cumprimento das exigências metabólicas dos astrócitos durante a prelactância. Objetivos. Avaliar a capacidade dos astrócitos para utilizar o aspartato como substrato metabólico em condições fisiológicas perinatais e determinar se a utilização de aspartato pode ser alterada por variações nas concentrações de glicose (Glc), lactato (Lac) e N-acetil-L-aspartato (NAA) e se estas alterações na concentração podem regular a atividade enzimática da ASPA. Materiais e métodos. Incubaram-se culturas quiescentes de astrócitos neonatais de ratos Wistar com L-aspartato $(0,5 \mathrm{mM})$ e L-[U- $\left.{ }^{14} \mathrm{C}\right]$-aspartato $(2 \mu \mathrm{Ci})$, para avaliar a sua capacidade de uso como substrato oxidativo e lipogênico. Determinou-se o efeito da variação das concentrações de Lac, Glc y NAA, e em condições fisiológicas perinatais como de adulto, sobre a utilização do aspartato (método radiométrico) e sobre a actividade do ASPA (método espectrofotométrico). Resultados. Demonstrou-se que os astrócitos estão em capacidade de usar o aspartato 87 vezes mais como substrato oxidativo do que lipogênico. Conclusões. O uso de aspartato e seu destino é afetado de forma significativa $(\mathrm{p}<0,05)$ pelas concentrações de Lac, Glc e ANA. ASPA tem uma alta atividade, sendo regulada pela disponibilidade de lactato e pelo aumento da disponibilidade de glicose.
\end{abstract}

Palavras-chave: aspartato, aspartoacilasa, astrócitos, prelactância

\section{Introducción}

Los astrocitos soportan la actividad neuronal por absorción del abundante glutamato intersticial y su transformación en glutamina a través de la glutamina sintetasa. La glutamina es suplementada a las neuronas como un mecanismo de transporte de carbonos y nitrógeno. Adicionalmente al suplemento de precursores para la síntesis de neurotransmisores, las neuronas necesitan sustratos energéticos para el normal funcionamiento del cerebro. El acople de la actividad neuronal con el metabolismo energético cerebral perinatal, implica al lactato como el principal producto final del metabolismo de la glucosa, que es liberado por los astrocitos como un sustrato energético para las neuronas, como consecuencia de la estimulación de la absorción de la glucosa evocada por el glutamato. El lactato es tomado por las neuronas, siendo el sustrato carbonado preferido para mantener la función sináptica (1). En trabajos previos del grupo, utilizando glucosa, lactato, 3-hidroxibutirato y acetato en concentraciones perinatales, se ha demostrado que tanto las neuronas como los astrocitos utilizan preferencialmente el lactato como sustrato energético y lipogénico $(2,3)$. Sin embargo, a pesar que se reconoce el importante papel de los astrocitos en el tráfico metabólico con las neuronas, aun falta considerar más mecanismos que regulan la selección de sustratos para la síntesis y liberación de precursores por estas células gliales. Por otro lado, hemos propuesto que un incremento en la disponibilidad del acetato y aspartato, podría ayudar a optimizar los recursos energéticos necesarios para mantener el metabolismo relacionado con la neurotransmisión y contribuir a la lipogénesis, principalmente de mielina, requeridos por el cerebro. El metabolismo del aspartato depende de las concentraciones de NADH dispo- nible en el citosol y la mitocondria para hacer funcional la lanzadera con el malato. El NADH puede provenir de las reacciones catalizadas por la gliceraldehído 3-fosfato deshidrogenasa y la lactato deshidrogenasa, ambas citosólicas (4). El aspartato intracerebral puede ser obtenido de diferentes rutas, la principal es vía aspartatoacilasa II (N-acilL-aspartato amidohidrolasa) (ASPA; EC 3.5.1.15), principal enzima catalítica del cerebro, que degrada el NAA, el segundo aminoácido más abundante después del glutamato en el sistema nervioso central (SNC) (5-7). La deficiencia de la enzima aspartatoacilasa II ocasiona la acumulación de NAA en el cerebro, lo cual provoca una degeneración de la materia blanca, conocida como enfermedad de Canavan $(8,9)$. El supuesto de que el aspartato puede tener un papel importante en el periodo perinatal se soporta con observaciones experimentales que confirman que durante el desarrollo cerebral hay una mayor actividad de las enzimas involucradas en la síntesis y degradación del Nacetil-L-aspartato (NAA) y del N-acetil-L-aspartil-Lglutamato (NAAG) sumado a una mayor expresión de transportadores de monocarboxilatos y a la expresión de transportadores específicos para aspartato y NAA en los astrocitos (3).

En el cerebro adulto la glucosa es el principal precursor del piruvato mitocondrial. Sin embargo, bajo ciertas condiciones como en prolongados períodos de inanición del cerebro adulto o durante el desarrollo temprano del cerebro, cuando la glucosa es incapaz de mantener la homeostasis cerebral, otros sustratos tales como lactato, 3hidroxibutirato, acetoacetato y glutamina (10-13) pueden ser utilizados como precursores metabólicos. Adicionalmente, el 3-hidroxibutirato, el acetoacetato y el acetato han demostrado ser sustratos de apoyo metabólico para la 
síntesis de acetil-CoA en células cerebrales (14-17). Se ha demostrado que el cerebro puede utilizar aminoácidos no esenciales como sustratos energéticos y lipogénicos en el periodo perinatal $(2,18)$.

\section{Metabolismo del aspartato}

Las neuronas y los astrocitos son capaces de tomar y metabolizar el aspartato. Experimentos con $\left[\mathrm{U}-{ }^{13} \mathrm{U}\right]-$ aspartato han demostrado que se marcan el lactato y el glutamato en ambos tipos de células. En los astrocitos también se encontró glutamina marcada e intermediarios del ciclo de los ácidos tricarboxílicos (TCA). La inhibición de la glucólisis con iodoacetato $(0,5 \mathrm{mM})$ claramente afecta la absorción y él metabolismo del aspartato en ambos cultivos (19).

El transporte de aspartato y glutamato es mediado por el mismo transportador expresado principalmente en los astrocitos (20,21). La entrada de glutamato en los astrocitos es un proceso que demanda energía ya que es cotransportado con dos o tres $\mathrm{Na}^{+}$los cuales tienen que ser removidos por la bomba de $\mathrm{Na}^{+} / \mathrm{K}^{+}$(22). Se ha demostrado que astrocitos preincubados con iodoacetato $(0,1 \circ 1 \mathrm{mM})$, causa una disminución de la absorción de glutamato a los 5 min (23). La liberación de glutamato al medio de incubación ha sido observada tanto en los controles como después de la inhibición de la glucólisis. Estudios en cortes de cerebro indican que entre un $10-15 \%$ del transporte de glutamato y aspartato puede ser responsable por homointercambio (glutamato/glutamato) y hetero-intercambio (glutamato/aspartato) a través de la membrana celular. El glutamato observado en el medio de cultivo puede deberse a este intercambio (24).

Por otro lado, se ha demostrado en experimentos de ${ }^{13} \mathrm{C}$ NMR utilizando como precursores $\left[\mathrm{U}-{ }^{13} \mathrm{C}\right]$-glutamato y [1$\left.{ }^{13} \mathrm{C}\right]$-glucosa, que los astrocitos son capaces de formar lactato vía piruvato derivado de intermediarios del TCA $(25,26)$. Adicionalmente, se ha comprobado que se obtiene $\left[\mathrm{U}-{ }^{13} \mathrm{C}\right]$-lactato en el medio de incubación de astrocitos usando como precursor al $\left[\mathrm{U}-{ }^{13} \mathrm{C}\right]$-aspartato (19). Después de la inhibición de la glucólisis no solamente no sale lactato marcado, sino que también el lactato derivado del aspartato es significativamente reducido. Estos resultados indican una reducción de la síntesis de piruvato desde oxalacetato y/o malato. De las reacciones comprometidas en este proceso, una descarboxila el oxalacetato a fosfoenolpiruvato y otra reduce el oxalacetato a malato, requiriendo GTP o NADH respectivamente.

El aspartato puede entrar al TCA después de su conversión a oxalacetato para ser usado para la producción de energía.
La presencia de $\left[1,2,3-{ }^{13} \mathrm{C}\right]$-glutamato y $\left[1,2,3-{ }^{13} \mathrm{C}\right]-$ glutamina en el cultivo de astrocitos demuestran el metabolismo de este sustrato en el TCA (26).

\section{Fuentes y transporte de aspartato en el cerebro}

Además de la mencionada lanzadera aspartato/malato en el cerebro existen otras fuentes de aspartato productos de la degradación de dos compuestos: el N-acetil-L-aspartato (NAA) y el N-acetil-L-aspartil-L-glutamato (NAAG). El NAA está en concentraciones altas en el cerebro de los mamíferos (6-10 $\mathrm{mmol} / \mathrm{g}$ de tejido) siendo el segundo aminoácido libre más abundante al lado del glutamato $(27,28)$. Estudios regionales en cerebro de ratón han demostrado la presencia de NAA en todas las áreas del cerebro con concentraciones más altas en materia gris cerebral (29). La concentración de NAA en cerebro humano aumenta 3 veces luego de la mitad de la gestación manteniendo este mismo nivel hasta la madurez (27). Durante la maduración cerebral, NAA se encuentra en neuronas así como en células gliales, pero está principalmente presente en neuronas durante el desarrollo del cerebro $(6,30,31)$. La concentración intraneuronal de NAA es 10 a 15 mM, mientras que la concentración extracelular de NAA en el espacio intersticial en el cerebro es de 80 a $100 \mu \mathrm{M}$ (32, 33). Dentro de las funciones del NAA aparte de ser el precursor del neuromodulador NAAG en neuronas (34), es la osmoregulación protegiéndolas contra el estrés osmótico $(33,35)$. La enzima responsable para la síntesis de NAA, la L-aspartato- $\mathrm{N}$-acetil transferasa, está presente exclusivamente en neuronas, sin embargo, la enzima responsable del rompimiento del NAA, la aspartatoacilasa II (ASPA), está presente predominantemente en células gliales (36, 37). Así, NAA se sintetiza en neuronas pero es hidrolizado a aspartato y acetato en células gliales.

El metabolismo glial de NAA ha mostrado ser importante para la síntesis de la mielina porque este compuesto es una de las principales fuentes de grupos del acetilo para la síntesis de lípidos durante desarrollo del cerebro (38). Los productos de la hidrólisis del NAA pueden ser tomados por las neuronas y por los astrocitos, aunque también se ha reportado que puede ser aprovechado por los oligodendrocitos (30). La existencia de los astrocitos tipo II se ha puesto de manifiesto in vivo por la presencia de células positivas al GFAP y al antígeno A2B5 en suspensiones celulares preparadas a partir de nervio óptico y cerebro de ratas de una semana de vida postnatal $(39,40)$. La proporción de este tipo de astrocitos es muy baja en cerebro adulto, por lo que se discute su función, e incluso, su existencia (41). Se ha demostrado que los astrocitos tipo II (O-2A) crecidos in vitro, sintetizan también NAA en concentra- 
ciones dos veces mayores que las neuronas. La concentración de NAA durante la maduración en el cerebro de rata incrementa rápidamente entre los 9 y 20 días después del nacimiento, un período activo de mielinización. El hecho que el NAA este en los O-2A sugiere que este compuesto es un donador de grupos acetilo para la síntesis de lípidos. Igualmente revela que existe una similitud entre los astrocitos tipo II y las neuronas, ya se ha reportado que expresan también algunas proteínas similares (31).

El transporte de todos los sustratos a las células nerviosas exige la existencia de sistemas de transporte específicos que se desarrollen con independencia a la formación de la barrera hematoencefálica (BHE). El sistema de transporte de monocarboxilatos que incluyen lactato, acetato, piruvato y butirato (42), cuerpos cetónicos (43) y acetoácidos (44) es mucho más activo en el cerebro en desarrollo, mientras que para la glucosa su actividad es mucho menor. Se ha demostrado la presencia de transportadores saturables para lactato y piruvato a través de la BHE (42).

Por otro lado el transporte de aminoácidos no sufre cambios marcados durante el desarrollo. Se ha reportado un transportador con alta afinidad para el NAA, el NaDC3 (6, 45), un transportador para L-aspartato (46) y un antiporte glutamato/aspartato dependiente de $\mathrm{Na}^{+}$(GLAST) (24), ambos se encuentran en la membrana plasmática de los astrocitos. Otros estudios muestran la existencia de un transportador para NAA en astrocitos de rata (45-46). Este transportador es saturable (constante de transporte, $\mathrm{Kt} \sim 80 \mu \mathrm{M}$ ), $\mathrm{Na}^{+}$y Cl- dependiente, y no interactúa recíprocamente con cualquier aminoácido. Se ha demostrado que transportadores de dicarboxilatos de alta afinidad acoplados a $\mathrm{Na}^{+}$ (NaDC3) son capaces de transportar NAA. El proceso de transporte es $\mathrm{Na}^{+}$-dependiente y electrogénico y exhibe un Kt de 100 a $250 \mu \mathrm{M}$ para NAA. Las características del transporte de NAA vía NaDC3 es exactamente el mismo a aquellos transportes de NAA descritos en células gliales.

\section{Materiales y métodos}

\section{Cultivos de astrocitos}

Cultivos primarios de astrocitos fueron preparados de cerebros de neonatos de un día de vida de ratas albinas Wistar. Las células fueron sembradas en frascos Roux con una densidad de $9 \times 10^{5}$ células $/ \mathrm{ml}$. Las células fueron mantenidas en medio Eagle modificado por Dulbecco (DMEM), al cual se le adicionó bicarbonato de sodio anhidro $(3.7 \mathrm{~g} /$ 1) y fue suplementado con suero fetal bovino (FBS) (10\%), ampicilina, estreptomicina, anfotericina y penicilina a $37^{\circ} \mathrm{C}$ en una incubadora con 5\% de $\mathrm{CO}_{2}$. Después de un seguimiento morfológico hasta los 14 días, los frascos con cul- tivos quiescentes de astrocitos se destinaron a los experimentos metabólicos y a realizar el contaje celular.

\section{Incubaciones}

Con el fin de conocer la capacidad del aspartato como sustrato oxidativo y lipogénico y poder medir las velocidades respectivamente, se empleó inicialmente medio de incubación Elliott (pH 7,38) (47) con aspartato $(0,5 \mathrm{mM})$ como sustrato frio y $\left[\mathrm{U}-{ }^{14} \mathrm{C}\right]$ - aspartato $(2 \mu \mathrm{Ci})$ como radiotrazador. A la monocapa de células se les adiciono $1.5 \mathrm{ml}$ del medio de incubación oxigenado con el sustrato frío. Luego, se sello herméticamente el frasco y se dejo incubando 1 hora a $37^{\circ} \mathrm{C}$. Paralelamente a estas incubaciones se realizaron otras adicionales para poder mirar si hay un efecto en la utilización del aspartato en presencia de otros sustratos. Se establecieron como concentraciones perinatales de glucosa $(2 \mathrm{mM})$, lactato $(10,5 \mathrm{mM})$ y $\mathrm{N}$ acetil-DL-aspartato (NAA) (20 mM) y las concentraciones de adulto de glucosa $(5 \mathrm{mM})$, L-lactato $(5 \mathrm{mM})$ y Nacetilaspartato $(10 \mathrm{mM})$. Cada una de las soluciones fue preparada en medio de incubación Elliot al que se le adiciono $2 \mu \mathrm{Ci}$ de $\mathrm{L}-\left[\mathrm{U}-{ }^{14} \mathrm{C}\right]$-aspartato. Los resultados de respiración y lipogénesis se compararon con respecto al aspartato $(0.5 \mathrm{mM})$.

\section{Cuantificación de $\mathrm{CO}_{2}$}

La captura y el conteo de $\mathrm{CO}_{2}$, se realizó siguiendo el método descrito por Sykes, con algunas modificaciones $(48,49)$, Para capturar el $\mathrm{CO}_{2}$, se utilizó un eppendorf con $500 \mu \mathrm{l}$ de hidróxido de hiamina que se encuentra en un matraz erlenmeyer. En el pozo principal se adicionaron $100 \mu \mathrm{l}$ de $\mathrm{KOH}(10 \mathrm{M})$ seguidamente se selló herméticamente con un tapón de goma. Sin destapar el frasco de cultivo, se extrajo con una jeringa el medio de incubación y se inyectó en el correspondiente matraz erlenmeyer previamente preparado. Se lavó la monocapa de células con PBS que, posteriormente, se recuperó en su respectivo matraz. Se inyectaron $2 \mathrm{ml}$ de $\mathrm{KOH}(0.3 \mathrm{M})$, colocando el frasco de manera que el $\mathrm{KOH}$ no hiciera contacto con las células y se pudiera capturar el $\mathrm{CO}_{2}$ remanente en el frasco de cultivo. Una hora después, el $\mathrm{KOH}$ fue retirado e inyectado en su respectivo matraz erlenmeyer. Se realizó otro lavado con PBS y, por último, una vez reunidos todos los volúmenes se adicionó $100 \mu \mathrm{l} \mathrm{de} \mathrm{HClO}_{4}(5 \mathrm{M})$ en el matraz erlenmeyer, con objeto de acidificar el medio y volatilizar el ${ }^{14} \mathrm{CO}_{2}$ que luego es capturado por la hiamina. Este proceso duro 1 hora. Seguidamente, se recogieron todos los tubos eppendorf que junto con el hidróxido de hiamina, se colocaron en viales. Luego, se les adiciono $5 \mathrm{ml}$ de líquido de centelleo, se agitaron por 30 segundos y se dejaron en reposo 16 horas para medir las desintegraciones por minu- 
to (dpm) utilizando la técnica de espectroscopia de centelleo líquido. La velocidad de respiración se calculó como nmol $\mathrm{CO}_{2} /$ hora/millón de células.

\section{Cuantificación de lípidos}

Para hacer la determinación de la incorporación de los sustratos en lípidos totales, se siguió el método de Folch, con ligeras modificaciones $(50,51)$. Para extraer los lípidos, la monocapa de células se separó del frasco de cultivo con ayuda de un raspador en $1 \mathrm{ml}$ de metanol, y se añadió a un tubo que contiene $2 \mathrm{ml}$ de cloroformo bidestilado). El tubo se agitó por 30 segundos y se almacenó durante 16 horas en el congelador. Posteriormente se centrifugará (1800 rpm, $\left.15 \mathrm{~min}, 4^{\circ} \mathrm{C}\right)$ y se lavo con $\mathrm{NaCl}(0.3 \%)$ saturado con cloroformo. La centrifugación se realizó en las condiciones anteriores, retirándose la fase acuosa y tomándose únicamente la fase clorofórmica. Esta última fase se evaporó y el residuo lipídico se disolvió en líquido de centelleo, el cual se agitó mecánicamente por 30 segundos y después de 24 horas, se midió la radiactividad incorporada en lípidos utilizando la técnica de espectroscopia de centelleo líquido. La velocidad de lipogénesis se calculó como nmol de lípidos/hora /millón de células.

\section{Determinación de proteínas}

La determinación de la concentración de proteínas se realizo teniendo en cuenta el método de Bradford (52).

\section{Actividad enzimática}

Homogeneizado. Se utilizo el método de Bhakoo (7) al cual se le realizaron algunas modificaciones. Se utilizaron células procedentes de astrocitos crecidos in vitro en cajas de Petri de $9 \mathrm{~cm}$ de diámetro. A los 14 días se retiró el medio de cultivo de cada una de las cajas de Petri en tubos de $50 \mathrm{ml}$ y las células se lavaron con $6 \mathrm{ml}$ de PBS. Una vez realizado esto, se extrajo el PBS por succión y se le adiciono $1 \mathrm{ml}$ de $\mathrm{CaCl}_{2}$ a cada una de las placas de la siguiente forma: primero se rasparon y se recogieron las células con $500 \mu \mathrm{l}$ y luego a cada caja se le adiciono $500 \mu \mathrm{l} \mathrm{CaCl}_{2}$ más para recoger las células remanentes. Las dos fracciones se recogieron en un tubo eppendorf. Posteriormente de una solución de $100 \mathrm{ml}$ de Tritón X-100, a cada eppendorf se les adicionó $10 \mu \mathrm{l}$ de esta solución para una concentración final $0.04 \%$, la suspensión fue homogenizada antes de que las muestras fueran sonicadas 2 veces por 10 segundos.

\section{Soluciones de incubación enzimática}

Las soluciones de incubación se realizaron en un tampón de Tris- $\mathrm{HCl}(0.1 \mathrm{M})$ pH 8.0 para evitar cambios drásticos de $\mathrm{pH}$. Se preparó $10 \mathrm{ml}$ de una solución a concentraciones fisiológicas perinatales de $\mathrm{N}$-acetil-DL-aspartato (NAA) (Sigma A-5625) (20 mM) de la cual se tomaron alícuotas para preparar $10 \mathrm{ml}$ de una solución de NAA $(2 \mathrm{mM})$ y 10 $\mathrm{ml}$ de una solución a concentraciones fisiológicas de adulto de NAA (10 mM). Adicionalmente se prepararon soluciones de $10 \mathrm{ml}$ a concentraciones fisiológicas de adulto: glucosa (5 mM) (Merck 1.08337) y L-lactato (5 mM) (Merck 366.0500) y a concentraciones fisiológicas perinatales: glucosa (2 mM), L-lactato $(10,5 \mathrm{mM})$ y L-aspartato $(0,5$ $\mathrm{mM}$ ) (Sigma A-6683). Antes de llevar a volumen (10 ml) a cada una de las soluciones de glucosa, aspartato y lactato se les adicionó una alícuota de NAA de manera que la concentración final fuera de $2 \mathrm{mM}$.

\section{Mezcla de reacción}

Para la mezcla de reacción se prepararon las siguientes soluciones en tampón de Tris- $\mathrm{HCl}(0,1 \mathrm{M}), \mathrm{pH} 8: 25 \mathrm{ml}$ de $\alpha$-cetoglutarato (30 mM) (Sigma K-1128); $1 \mathrm{ml}$ de malato deshidrogenasa (MDS) (Calbiochem 442610) y $\beta$-NADH (Sigma N-8129).La mezcla de reacción se preparó a partir de $1 \mathrm{ml}$ de $\alpha$-cetoglutarato, $1 \mathrm{ml}$ de $\beta$-NADH $(1,5 \mathrm{mM})$ y $10 \mu \mathrm{l}$ de la enzima malato deshidrogenasa (MDS). La mezcla se llevó a un volumen final de $6,5 \mathrm{ml}$ con buffer de Tris$\mathrm{HCl}(0,1 \mathrm{M}), \mathrm{pH} 8$ y se homogenizó mecánicamente durante 1 minuto.

\section{Mezcla del homogenizado}

Se tomaron $200 \mu \mathrm{l}$ de cada homogenado y se mezclaron con $200 \mu \mathrm{l}$ de cada una de las soluciones previamente preparadas para el ensayo enzimático. Adicionalmente, para el blanco se tomaron $200 \mu \mathrm{l}$ del homogenado y se mezclaron con $200 \mu \mathrm{l}$ de buffer de Tris- $\mathrm{HCl}(0,1 \mathrm{M}), \mathrm{pH}$ 8. Esto mismo se realizo para el medio de cultivo, a partir del cual se tomaron $200 \mu \mathrm{l}$ y se mezclaron con $200 \mu \mathrm{l}$ de buffer de Tris- $\mathrm{HCl}(0,1 \mathrm{M})$. Todas las soluciones fueron incubadas a $37^{\circ} \mathrm{C}$ por 2 horas. Posteriormente se paró la reacción calentando a $100{ }^{\circ} \mathrm{C}$ durante 10 minutos para desnaturalizar proteínas. Luego, cada mezcla fue centrifugada a 1800 rpm por 2 minutos para remover el precipitado proteico.

\section{Lectura de Datos}

A partir del homogenado se tomaron $300 \mu \mathrm{l}$ del sobrenadante y se mezclaron con $1.2 \mathrm{ml}$. de la mezcla de reacción en tubos de vidrio. Luego, cada uno de los tubos se incubo a $37^{\circ} \mathrm{C}$ por cinco minutos y transcurrido este tiempo de incubación, se les midió la absorbancia inicial a $340 \mathrm{~nm}$ con un espectrofotómetro (Genesis20).Antes de realizar las lecturas de absorbancia a $340 \mathrm{~nm}$ se empleo un blanco de $1.5 \mathrm{ml}$ de solución buffer para ajustar el 0 de absorbancia. 
Una vez realizada la lectura inicial, se le adicionó a cada una de las muestras $5 \mu \mathrm{l}$ de la enzima aspartato aminotransferasa (ATT) (Calbiochem 351800) y las soluciones se dejaron incubando a $37{ }^{\circ} \mathrm{C}$ por 2 horas para medir la absorbancia final a $340 \mathrm{~nm}$ en estas condiciones.

\section{Tratamiento estadístico}

Los experimentos se realizaron de acuerdo con un diseño completamente aleatorizado con 3 replicas con quintuplicado por experimento para astrocitos $(n=15)$. Los resultados obtenidos del efecto sobre la utilización del aspartato con diferentes concentraciones de sustrato se analizaron estadísticamente por medio del programa de Microsoft Excel. A los cuales se les realizó un análisis de varianza (ANOVA). Se hicieron comparaciones múltiples a los resultados de actividad específica (DUNCAN).

\section{Resultados y discusión}

\section{Utilización del aspartato}

Los resultados de respiración y lipogénesis obtenidos en este trabajo (Tabla 1), evidencian la utilización del aspartato tanto para la respiración $(1,48 \pm 0,28 \mathrm{nmol} \mathrm{CO} /$ $\mathrm{h} / 10^{6}$ células) como para la lipogénesis $(0,017 \pm 0,003$ nmol lípidos $/ \mathrm{h} / 10^{6}$ células) a partir de la utilización del L$\left[\mathrm{U}-{ }^{14} \mathrm{C}\right]$-aspartato en condiciones perinatales en los cultivos quiescentes de astrocitos. No obstante, estos resultados sugieren que el aspartato es utilizado 87 veces más para la respiración que para la lipogénesis. Adicionalmente, confirman la existencia de transportadores específicos para este sustrato. La liberación de sustratos energéticos de la sangre al cerebro requiere de un sistema de transporte entre las células endoteliales involucradas en la barrera hematoencefálica y las membranas celulares de los astrocitos $(53,54)$. En los astrocitos, en la membrana plasmática, ha sido reportado previamente un transportador GLAST, de alta afinidad para L-glutamato, L-aspartato y D-aspartato. Este transportador depende de las concentraciones de sodio y es independiente de cloro y su expresión se ve aumentada principalmente en el día 1 postnatal (55). La existencia del transportador GLAST a nivel de membrana plasmática en los astrocitos asegura la entrada del aspartato exógeno que puede ser utilizado por diferentes vías. Por otra parte, se ha encontrado que el L-aspartato es rápidamente transportado en los cultivos de astrocitos, en experimentos llevados a cabo con L-aspartato (1-1000 $\mu \mathrm{m})$, la absorción de este aminoácido a una concentración de $500 \mu \mathrm{mol}$ tiene una duración de 15 segundos (56). Esto

Tabla 1. Efecto sobre la utilización del aspartato como sustrato oxidativo y lipogénico causado por diferentes sustratos.

\begin{tabular}{|c|c|c|}
\hline \multicolumn{3}{|l|}{ ASTROCITOS } \\
\hline \multirow[t]{2}{*}{ Sustratos } & Respiración & Lipogénesis \\
\hline & nmol $\mathrm{CO}_{2} / \mathrm{h} / 10^{6}$ de células & nmol lípidos/h/10'de células \\
\hline $\operatorname{Asp}(0,5 \mathrm{mM})$ & $1,480 \pm 0,280$ & $0,0170 \pm 0,0030$ \\
\hline \multicolumn{3}{|l|}{ Condiciones Perinatales } \\
\hline $\operatorname{Asp}(0,5 \mathrm{mM})+\mathrm{Glc}(5 \mathrm{mM})$ & $0,376 \pm 0,062^{*}$ & $0,0100 \pm 0,0030^{*}$ \\
\hline $\operatorname{Asp}(0,5 \mathrm{mM})+\operatorname{Lac}(10,5 \mathrm{mM})$ & $0,129 \pm 0,025^{*}$ & $0,0850 \pm 0,0150^{*}$ \\
\hline $\operatorname{Asp}(0,5 \mathrm{mM})+\mathrm{NAA}(20 \mathrm{mM})$ & $0,023 \pm 0,004^{*}$ & $0,0013 \pm 0,0003^{*}$ \\
\hline \multicolumn{3}{|l|}{ Condiciones adulto } \\
\hline $\operatorname{Asp}(0,5 \mathrm{mM})+\mathrm{Glc}(2 \mathrm{mM})$ & $1,580 \pm 0,350$ & $0,0360 \pm 0,0100$ \\
\hline $\operatorname{Asp}(0,5 \mathrm{mM})+\operatorname{Lac}(5 \mathrm{mM})$ & $0,160 \pm 0,040^{*}$ & $0,0800 \pm 0,0100^{*}$ \\
\hline $\operatorname{Asp}(0,5 \mathrm{mM})+\mathrm{NAA}(10 \mathrm{mM})$ & $0,186 \pm 0,043^{*}$ & $0,0014 \pm 0,0002 *$ \\
\hline \multicolumn{3}{|c|}{ 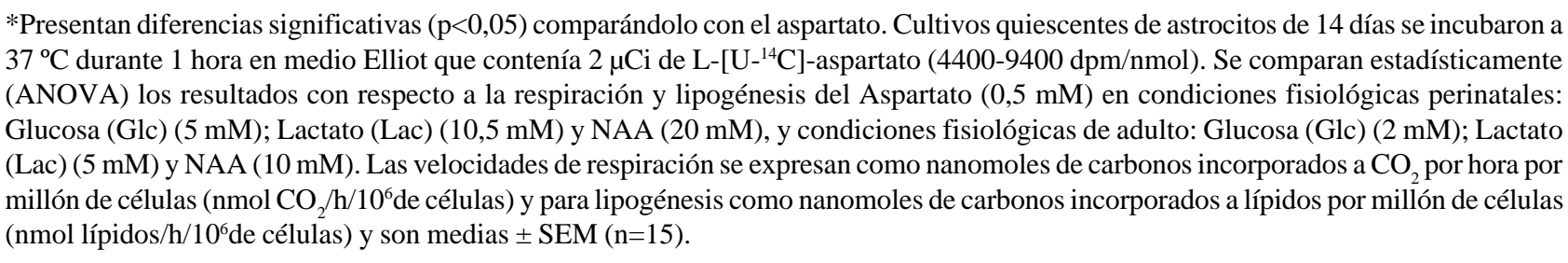 } \\
\hline
\end{tabular}


sugiere que los astrocitos poseen un sistema de transporte muy a fin a este aminoácido, lo cual permite que sea rápidamente metabolizado y utilizado en estas células.

Adicionalmente, en la membrana mitocondrial, también han sido reportados otros dos tipos de transportadores, que son antiportes de glutamato/aspartato denominados SLC25A12 (Aralar1) y SLC25A13 (Citrin) y dependen de las concentraciones de $\mathrm{Ca}^{+2}$. Estos sistemas de transporte facilitan la entrada del aspartato al mitosol de los astrocitos para que pueda ser metabolizado por estas células.

Con base en los resultados obtenidos se evidencia que el $\mathrm{L}-\left[\mathrm{U}-{ }^{14} \mathrm{C}\right]$-aspartato no es un buen precursor lipogénico y que si se hubiese utilizado por la vía de cME se esperaría un aumento más acentuado en la lipogénesis, no obstante, si se tiene en cuenta que una disminución del aspartato citosólico causa un incremento en la oxidación del citrato, se vería disminuido el aporte de este sustrato como precursor lipogénico (57). Sin embargo, el [U- $\left.{ }^{14} \mathrm{C}\right]$-oxalacetato citosólico puede tomar la vía de la fosfoenolpiruvato carboxiquinasa (PEPK), producir $\left[\mathrm{U}-{ }^{14} \mathrm{C}\right]$-fosfoenolpiruvato que sería precursor del $\left[\mathrm{U}^{14} \mathrm{C}\right]$-glicerol-3-fosfato utilizado para la síntesis de fosfolípidos y que explicaría la pequeña contribución del aspartato en la lipogénesis.

\section{Efecto de otros sustratos sobre la utilización de aspartato como sustrato metabólico}

Los resultados obtenidos con aspartato al compararse con los obtenidos a partir de la variación en las concentraciones de glucosa, NAA y lactato (Tabla 1) evidencian que la utilización de aspartato puede variar de acuerdo a las concentraciones perinatales y de adulto utilizadas durante las incubaciones con estos sustratos, encontrándose diferencias significativas $(\mathrm{p}<0,05)$ en la utilización de aspartato con glucosa, NAA y lactato en condiciones perinatales y diferencias significativas $(\mathrm{p}<0,05)$ con lactato y NAA en condiciones de adulto para respiración y lipogénesis.

\section{Comparación en condiciones perinatales.}

\section{Efecto de la glucosa}

Se evidencio que la glucosa en concentraciones fisiológicas perinatales $(5 \mathrm{mM})$ influye sobre la utilización del L-[U$\left.{ }^{14} \mathrm{C}\right]$-aspartato significativamente $(\mathrm{p}<0,05)$, disminuyendo así la utilización de este como fuente de carbonos en el TCA. La explicación de este evento es que están entrando mas carbonos fríos procedentes del piruvato obtenido por vía glucolítica, que producirían mas acetil-CoA fría y oxalacetato (OAA) frio que el que podría aportar el aspartato. Estos resultados indican que el incremento de las concentraciones citosólicas de piruvato estaría modulando la actividad de la enzima málica citosólica (cME) y que el incremento de las concentraciones de OAA mitocondrial estaría modulando la actividad de la lanzadera del aspartato/malato.

Adicionalmente estos resultados también están reflejando el estado metabólico de los astrocitos, demostrando así que en presencia de glucosa $(5 \mathrm{mM})$, se incrementan las tasas de oxidación en estos y por tanto la respiración desde la utilización de aspartato no es muy relevante en presencia de estas concentraciones de glucosa. Paralelamente esto se puede corroborar a partir de estudios que se han realizado con cultivos primarios de astrocitos, en donde se han utilizado concentraciones de glucosa en el orden de 6 a 7 $\mathrm{mM}$, y las tasas de respiración celular se ven incrementadas (58).

Por otro lado, la disminución significativa $(\mathrm{p}<0,05)$ en la utilización del L-[U- $\left.{ }^{14} \mathrm{C}\right]$-aspartato como sustrato lipogénico en presencia de glucosa $(5 \mathrm{mM})$, corroboran los resultados de respiración indicando que efectivamente la vía del citrato no es una ruta lipogénica a partir del aspartato, sin embargo, la disminución de los lípidos marcados vía glicerol-3-fosfato se ve influenciada por la contribución al reservorio de este sustrato por vía glucolítica.

\section{Efecto del lactato}

Los resultados obtenidos a partir de concentraciones fisiológicas perinatales de lactato $(10.5 \mathrm{mM})$, presentaron una disminución significativa $(\mathrm{p}<0,05)$ en la utilización del L$\left[\mathrm{U}-{ }^{14} \mathrm{C}\right]$-aspartato como sustrato oxidativo, y corroboran los resultados obtenidos con glucosa $(5 \mathrm{mM})$ en el sentido que, al verse favorecido un incremento de piruvato se ven reguladas las vías de la cME y la lanzadera aspartato/malato. Adicionalmente, el lactato que es rápidamente absorbido por los astrocitos en estas condiciones puede ser utilizado más rápidamente para la síntesis del OAA vía piruvato carboxilasa (PC) que el piruvato procedente de la glucosa.

Aun cuando su utilización disminuye notablemente, esta no alcanza a ser nula y se evidencia que algo de aspartato podría ser utilizado endógenamente. Estos resultados demuestran que las tasas de oxidación en los astrocitos durante esta etapa de prelactancia no solo se ven inducidas e incrementadas principalmente por el lactato presente en el medio, sino que también este es utilizado mayormente como un sustrato directo de energía y proveedor de esqueletos de carbonos para la síntesis de intermediarios del TCA.

Por otro lado, el incremento significativo $(\mathrm{p}<0,05)$ en la utilización del L-[U- $\left.{ }^{14} \mathrm{C}\right]$-aspartato como precursor lipogé- 
nico en presencia de lactato $(10,5 \mathrm{mM})$, señala el incremento de las necesidades de glicerol-3-fosfato procedentes del aspartato para la síntesis de fosfolípidos, ya que el lactato estaría siendo utilizado preferentemente para la síntesis de ácidos grasos, necesarios para la formación de membranas que en este periodo esta incrementado. En los astrocitos, se ha demostrado que el lactato es uno de los principales precursores de lípidos durante el periodo neonatal temprano $(11,51)$.

\section{Efecto del N-acetilaspartato (NAA)}

Los resultados obtenidos a partir de concentraciones fisiológicas perinatales de $\mathrm{N}$-acetilaspartato (NAA) (20 $\mathrm{mM})$, presentaron una disminución significativa $(p<0,05)$ en la utilización del L-[U- $\left.{ }^{14} \mathrm{C}\right]$-aspartato como sustrato oxidativo. Estos resultados están reflejando una alta actividad de la aspartoacilasa II (ASPA) que hidroliza el NAA citosólico a aspartato y acetato, incrementando así los reservorios de aspartato y acetato frio en el citosol. Este incremento de aspartato refleja que el NAA induce la activación de esta enzima, adicionalmente, el aspartato producido a partir de NAA $(20 \mathrm{mM})$ es mucho mayor al aspartato marcado utilizado en las incubaciones $(0,5 \mathrm{mM})$. El aspartato frio proveniente de la hidrólisis de NAA es transaminado por la aspartato aminotransferasa citosólica (ATT) formando así OAA frio que daría más malato frio que entraría al TCA produciendo $\mathrm{CO}_{2}$ sin marcar.

Por otra parte, la disminución significativa $(\mathrm{p}<0,05)$ en la utilización del L-[U- $\left.{ }^{14} \mathrm{C}\right]$-aspartato como sustrato lipogénico en presencia de NAA ( $20 \mathrm{mM})$, refleja los mismo que los resultados de respiración, actividad de la aspartoacilasa II (ASPA) que causa un incremento del reservorio de OAA frio y una disminución de la disponibilidad de [U$\left.{ }^{14} \mathrm{C}\right]$-glicerol-3-fosfato para la síntesis de fosfolípidos.

\section{Comparación en condiciones adulto}

\section{Efecto de la glucosa}

Los resultados obtenidos para respiración reflejan no hay ningún efecto en cuanto la utilización del L-[U- $\left.{ }^{14} \mathrm{C}\right]-$ aspartato como sustrato oxidativo (Tabla 1). Esto sugiere que en estas condiciones, la síntesis de piruvato no es suficiente para mantener el reservorio de OAA por medio de la piruvato carboxilasa (PC), demostrándose que efectivamente la actividad de esta enzima está condicionada por el suplemento de piruvato. Por lo tanto, se activa la lanzadera aspartato/malato que contribuye a suplementar el reservorio de OAA en la mitocondria que se ve favorecida en el adulto. Igualmente, refleja la necesidad del apoyo del lactato para el mantenimiento del reservorio de OAA.

Por otro lado, el incremento significativo $(p<0,05)$ en la utilización del L-[U- $\left.{ }^{14} \mathrm{C}\right]$-aspartato como sustrato lipogénico en presencia de glucosa $(2 \mathrm{mM})$, refleja un incremento de la actividad de la aspartato aminotransferasa citosólica que incrementaría el reservorio de $\left[\mathrm{U}-{ }^{14} \mathrm{C}\right]$-oxalacetato que, como ya se ha sostenido, sería un precursor de $\left[\mathrm{U}_{-}{ }^{14} \mathrm{C}\right]-$ glicerol-3-fosfato, sin embargo, los astrocitos en condiciones de adulto no tienen incrementada su necesidad de síntesis de fosfolípidos, este resultado puede estar indicando que en estas condiciones se activa la cME que favorecería la síntesis de ácidos grasos.

\section{Efecto del lactato}

Los resultados obtenidos para respiración reflejan que el lactato $(5 \mathrm{mM})$ influyó significativamente $(\mathrm{p}<0,05)$ causando una disminución en cuanto la utilización del L-[U$\left.{ }^{14} \mathrm{C}\right]$-aspartato como sustrato oxidativo. Este resultado señala la importancia del lactato no sólo a en condiciones fisiológicas de adulto, sino también, en condiciones fisiológicas perinatales como un sustrato clave para mantener los reservorios de OAA para el TCA. Lo que demuestra es que a estas concentraciones de adulto, el lactato sigue siendo un buen precursor de piruvato y como consecuencia la síntesis de OAA no se ve disminuida como para utilizar otros sustratos como el aspartato para la formación de este.

Igualmente, los resultados indican que la presencia de lactato influyó significativamente $(\mathrm{p}<0,05)$ causando un incremento en cuanto la utilización del L-[U- $\left.{ }^{14} \mathrm{C}\right]$-aspartato como sustrato lipogénico indicando que en estas condiciones, se activa la cME, que favorecería la síntesis [U$\left.{ }^{14} \mathrm{C}\right]$-acetil-CoA como precursor de ácidos grasos y se ve limitada la actividad de la lanzadera aspartato/malato.

\section{Efecto del N-acetilaspartato (NAA)}

El NAA en concentraciones de $(10 \mathrm{mM})$ influyó significativamente $(p<0,05)$ causando una disminución en cuanto la utilización del L-[U- $\left.{ }^{14} \mathrm{C}\right]$-aspartato como sustrato oxidativo. Sin embargo, los resultados evidencian que a estas concentraciones se activa la lanzadera aspartato/malato permitiendo que entre más $\mathrm{L}-\left[\mathrm{U}-{ }^{14} \mathrm{C}\right]$-malato para suplir las necesidades de OAA mitocondrial.

En cuanto al efecto del NAA en concentraciones de (10 $\mathrm{mM})$ influyó significativamente $(\mathrm{p}<0,05)$ causando una disminución en la utilización del L-[U- $\left.{ }^{14} \mathrm{C}\right]$-aspartato como sustrato lipogénico. Estos resultados reflejan la actividad 
de la aspartoacilasa II (ASPA) que causa un incremento del reservorio de OAA frio y por lo tanto de malato frio.

\section{Actividad enzimática de la aspartoacilasa (ASPA) en cultivos primarios de astrocitos en presencia de sustratos metabólicos en condiciones perinatales y de adulto.}

Los resultados obtenidos (Tabla 2) demuestran la presencia de esta enzima en los astrocitos. La comparación entre los diferentes sustratos utilizados en las condiciones perinatales y de adulto, sugiere una mayor actividad en presencia de NAA, aspartato y glucosa. No obstante, la variación de la concentración de NAA comparada con el referente $(2 \mathrm{mM})$ no generó un aumento o disminución significativo en la actividad de la enzima $(\mathrm{p}<0,05)$. Por otra parte la glucosa y el lactato en condiciones perinatales al Valores con la misma letra no presentan diferencias significativas $(p<0,05)$ igual que el lactato en condiciones adultas si tienen un efecto significativo $(\mathrm{p}<0,05)$ sobre la actividad enzimática.

\section{Modificaciones al protocolo de referencia (7).}

En los resultados obtenidos a partir del ensayo enzimático se tomo como valor de referencia el NAA $(2 \mathrm{mM})$, principalmente porque esta concentración fue reportada anteriormente por Bhakoo (7) quienes determinaron la actividad de la aspartoacilasa II (ASPA) en cultivos de astrocitos tipo I y astrocitos tipo II, adicionalmente, también se reporta la diferencia en la actividad enzimática en astrocitos tipo I durante un periodo de 14 días de incubación in vitro. Por otro lado, Bhakoo realizo los cultivos de astrocitos tipo I y tipo II respectivamente a partir de astrocitos corticales de ratas adultas, mientras que los cultivos realizados de astrocitos en este estudio, provienen de neonatos de ratas de 1 dia de vida posnatal. Adicionalmente, los resultados sobre la actividad enzimática están reportados a partir de cultivos de astrocitos tipo I $(0,643 \pm 0,172$, nmol de aspartato/min/mg proteína) y astrocitos tipo II $(2,832 \pm 0,785, \mathrm{nmol}$ de aspartato/min/mg proteína) los cuales, en suma dan un actividad de 3,475 de nmol de aspartato/min/mg proteína. En este estudio se trabajo un cocultivo de astrocitos (mezcla de astrocitos tipo I y II) el

Tabla 2. Actividad enzimática de la aspartoacilasa II (ASPA)

\begin{tabular}{lccc}
\hline & $\begin{array}{c}\text { Inicio } \\
\mathbf{0} \text { min. }\end{array}$ & $\begin{array}{c}\text { Final } \\
\mathbf{1 2 0} \text { min. }\end{array}$ & $\begin{array}{c}\text { Actividad especifica } \\
\text { (nmoles de Asp/min/mg proteína) }\end{array}$ \\
\hline Solución Patrón (NADH 1,5 mM) & $2,405 \pm 0,003$ & & \\
Control (homogenado) & $0,165 \pm 0,015$ & $0,121 \pm 0,014$ & $0,135 \pm 0,021 \mathrm{~B}$ \\
Medio de cultivo & $0,118 \pm 0,023$ & $0,105 \pm 0,023$ & $0,165 \pm 0,017 \mathrm{~B}$ \\
NAA (2 mM)(7) & $1,822 \pm 0,126$ & $0,524 \pm 0,132$ & $3,111 \pm 0,151 \mathrm{~A}$ \\
\hline
\end{tabular}

\section{Sustratos}

\section{Condiciones Perinatales}

\begin{tabular}{llll}
\hline NAA $(20 \mathrm{mM})$ & $1,310 \pm 0,456$ & $0,469 \pm 0,110$ & $2,720 \pm 0,582 \mathrm{~A}$ \\
Asp $(0,5 \mathrm{mM})+$ NAA $(2 \mathrm{mM})$ & $1,993 \pm 0,474$ & $0,538 \pm 0,111$ & $2,964 \pm 0,688 \mathrm{~A}$ \\
Glc $(5 \mathrm{mM})+$ NAA $(2 \mathrm{mM})$ & $0,115 \pm 0,016$ & $0,077 \pm 0,005$ & $0,056 \pm 0,003 \mathrm{C}$ \\
Lac $(10,5 \mathrm{mM})+$ NAA $(2 \mathrm{mM})$ & $0,116 \pm 0,016$ & $0,103 \pm 0,020$ & $0,021 \pm 0,001 \mathrm{D}$
\end{tabular}

\section{Condiciones Adulto}

\begin{tabular}{llll}
\hline NAA $(10 \mathrm{mM})$ & $1,402 \pm 0,407$ & $0,411 \pm 0,275$ & $2,673 \pm 0,362 \mathrm{~A}$ \\
Glc $(2 \mathrm{mM})+$ NAA $(2 \mathrm{mM})$ & $1,802 \pm 0,257$ & $0,682 \pm 0,179$ & $2,688 \pm 0,469 \mathrm{~A}$ \\
Lac $(5 \mathrm{mM})+$ NAA $(2 \mathrm{mM})$ & $0,108 \pm 0,002$ & $0,079 \pm 0,0012$ & $0,058 \pm 0,011 \mathrm{C}$ \\
\hline
\end{tabular}

Se utilizo un cocultivo astrocitos quiescentes (tipo I y tipo II) de 14 días, fueron cosechados e incubados a $37^{\circ} \mathrm{C}$ por 2 horas en presencia de NADH $(1,5 \mathrm{mM}), \alpha$-cetoglutarato $(30 \mathrm{mM})$, malato deshidrogenasa NADH dependiente (MDH) $(10 \mu \mathrm{l})$ y aspartato aminotransferasa (ATT) $(5 \mu \mathrm{l})$ preparados en una solución buffer Tris-HCl 0,1 M pH 8,0. Se determino el efecto sobre la actividad de la aspartoacilasa II (ASPA) (nmol/min/mg proteína) según el método de Bhakoo (7) midiendo la variación inicial y final de la oxidación del NADH a 340 nm con diferentes sustratos en concentraciones fisiológicas perinatales y de adulto y son medias \pm SEM ( $\mathrm{n}=15$ ). (DUNCAN). 
cual da una actividad específica de 3,111 $\pm 0,151$ de nmol de aspartato/min/mg proteína para NAA $2 \mathrm{mM}$ resultado que es comparable con la suma de las actividades específicas reportadas por Bhakoo y nos indican que se hizo una buena adaptación del protocolo reportado. Adicionalmente, se trabajo el cocultivo a los 14 días de incubación in vitro momento en el que se ve la máxima actividad de la enzima en el cultivo de astrocitos tipo I (7).

Por otra parte los resultados obtenidos con el control de células indican en el homogenado de los astrocitos hay una alta concentración de oxalacetato (OAA) que consumió el NADH rápidamente cuando se le adiciono la malato deshidrogenasa (MDH), por lo tanto, las reservas de OAA disponibles en los astrocitos esta incrementada después de dos horas de incubación lo que refleja una alta actividad de la aspartato aminotransferasa (ATT). Cuando se hizo la incubación final con ATT los resultados indican que efectivamente había una baja concentración de aspartato libre. Los resultados iníciales y finales de absorbancia para el medio de cultivo reflejan lo mismo, una alta concentración de oxalacetato en la primera incubación y una baja concentración de aspartato en la incubación final.

\section{Comparación de las variaciones de concentración del NAA y Aspartato.}

El NAA aparentemente no tiene una función reguladora sobre la actividad de la aspartoacilasa II y por lo tanto la variación de la concentración de este sustrato no influye sobre su actividad específica. Comparando las tres concentraciones empleadas para NAA $(2,10$ y $20 \mathrm{mM})$ se evidencio que la actividad específica de la ASPA no varió significativamente $(p<0,05)$. Los valores iníciales de absorbancia de la incubación inicial para cada una de estas soluciones sugieren una baja concentración de OAA y la incubación final demuestra una alta concentración de aspartato tanto en condiciones perinatales $(20 \mathrm{mM})$ como en adulto $(10 \mathrm{mM})$. Estos resultados evidencian que hay una diferencia en el tamaño de los reservorios de OAA y aspartato en los astrocitos. No se puede asumir que una alta concentración de aspartato produzca una alta concentración de OAA ya que este proceso depende la actividad de ATT. Adicionalmente, cuando se incluyó aspartato $(0,5$ $\mathrm{mM}$ ) tampoco se evidencio una variación significativa en la concentración de aspartato ni en la actividad de la enzima. Los resultados indican que no hay efecto sobre la actividad de la enzima cuando se tienen variaciones de la concentración de NAA en condiciones perinatales y en adulto.

Comparación de las variaciones de concentración de la glucosa. Los resultados señalan que a concentraciones de adulto de glucosa $(2 \mathrm{mM})$ no hay un efecto significativo $(\mathrm{p}<0,05)$ sobre la actividad de la enzima. Sin embargo, cuando las concentraciones de glucosa se ven incrementadas como en el periodo perinatal $(5 \mathrm{mM})$ la actividad de la enzima si se ve afectada significativamente. Estos resultados indican que la concentración de glucosa si afecta la actividad de la enzima, y que en concentraciones perinatales de glucosa, se ve inhibida la absorción del NAA por los astrocitos posiblemente para favorecer la utilización del NAA por los oligodendrocitos como sustrato lipogénico.

\section{Comparación de las variaciones de concentración de lactato}

El efecto sobre la actividad enzimática en presencia de lactato en concentraciones perinatales $(10.5 \mathrm{mM})$ y lactato adulto ( $5 \mathrm{mM})$ es muy similar a las encontradas con glucosa $(5 \mathrm{mM})$. Las concentraciones de lactato inhiben significativamente $(\mathrm{p}<0,05)$ la actividad de la enzima. Estos resultados indican que si los reservorios de lactato son grandes no existe la necesidad por los astrocitos de suplementar el reservorio de OAA mitocondrial critico en estos dos estados del desarrollo.

Adicionalmente, durante el periodo de prelactancia la demanda energética y oxidación de sustratos en los astrocitos se evidencia que es mucho mayor, razón por la cual las células se ven en la necesidad de estar sintetizando intermediarios que sirvan de precursores de otros sustratos para abastecer sus requerimientos metabólicos y el de otras células como las neuronas. Esto mismo puede ser corroborado por los resultados obtenidos, ya que se evidencio que a estas concentraciones de glucosa se promueve la utilización de aspartato en los astrocitos para lograr mantener la respiración que es crítica en este momento del desarrollo del sistema nervioso central.

\section{Conclusiones}

Se demostró que los astrocitos en condiciones perinatales pueden utilizar el aspartato como un sustrato metabólico alternativo. Sin embargo, su utilización en estas células está orientada principalmente para mantener la continuidad del ciclo de los ácidos tricarboxilicos (TCA) y a su vez la síntesis de intermediarios metabólicos. Mientras que su utilización para la síntesis de lípidos no es muy relevante y su contribución puede estar relacionada con la síntesis de glicerol-3-fosfato, precursor de glicerofosfolípidos. Adicionalmente, la disponibilidad de glucosa, lactato y NAA pueden modificar en los astrocitos la utilización del aspartato. Llama la atención que la presencia de lactato favorece la utilización del aspartato por vía lipogénica. 
Se pudo corroborar la presencia en los astrocitos de la enzima aspartoacilasa II (ASPA), demostrándose que durante el periodo de prelactancia la actividad de esta enzima es alta y que puede variar en presencia de otros sustratos como el NAA, glucosa, lactato y aspartato, dependiendo de las condiciones si son perinatales o de adulto. La mayor actividad se reporto en presencia de NAA aun cuando este sustrato es especifico para esta enzima, la variación de su concentración no influye significativamente $(\mathrm{p}<0,05)$ sobre la actividad de ASPA. Adicionalmente, la actividad de la enzima no es afectada por concentraciones de aspartato (0,5 mM). Sin embargo, la actividad de la enzima si está siendo regulada por disponibilidad de lactato y por el incremento de la disponibilidad de glucosa.

\section{Agradecimientos}

Los autores agradecen a Angélica Pinzón por su colaboración en el mantenimiento de los animales de experimentación en el Bioterio de la Facultad de Ciencias (PUJ).

\section{Financiación}

La Vicerrectoría Académica de la Pontificia Universidad Javeriana dio su apoyo financiero para la elaboración de este trabajo (proyecto 1769).

\section{Conflicto de intereses}

Los autores declaran que no existen conflictos de intereses con este trabajo.

\section{Referencias}

1. Zwingmann $\mathrm{C}$, Richter-Landsberg C, Leibfritz D. ${ }^{13} \mathrm{C}$ isotopomer analysis of glucose and alanine metabolism reveals cytosolic pyruvate compartmentation as part of energy metabolism in astrocytes. Glia. 2001; 34:200-212.

2. Medina J, Tabernero J, Tovar J, Martin-Barrientos J. Metabolic fuel utilization and pyruvate oxidation during the postnatal period. Journal of Inherited Metabolic Disease. 1996; 19:432-442.

3. Tovar J, Saavedra L, Bryon A. Metabolismo cerebral, En: Neuroanestesia. Enfoque perioperatorio en el paciente neurológico., Ferrer M, Niño L. (eds.). Distribuna Editorial Médica: Bogotá D.C. 2005; p.33-88

4. Gibson G, Blass J. A relation between [NAD $\left.{ }^{+}\right] /[\mathrm{NADH}]$ potentials and glucose utilization in rat brain slices. The Journal of Biological Chemistry. 1976; 251(13): 4127-4130.
5. Nikolaj T, Thomsen C, Valsborg J, Laursen H, Hansen A. Astroglia contain a specific transport mechanism for N- Acetyl-L-Aspartate. Journal of Neurochemistry. 1999; 73(2):807-811.

6. Huang W, Wang H, Kekuda R, Fei Y, Friedrich A, Wang J, Conway S, Cameron R, Leibach F, Ganapathy $\mathrm{V}$. Transport of N-Acetylaspartate by the Na-dependent hight- affinity dicarboxylate transporter NADC3 and its relevance to expression of the transporter in the brain. The Journal of Pharmacology and Experimental Therapeutics. 2000; 295(1):392-403.

7. Bhakoo K, Craig T, Styles P. Developmental and regional distribution of aspartoacylase in rat brain tissue. Journal of Neurochemistry. 2001; 79:211-220.

8. Matalon R, Michals-Malaton K. Biochemistry and molecular biology of Canavan disease. Neurochemical Research. 1999; 24:507-513.

9. Chang K, Adleman N, Dienes K, Barnea-Goraly N, Reiss A, Ketter T. Decreased N-acetylaspartate in children with familial bipolar disorder. Biological Psychiatry. 2003; 53:1059-1065.

10. Cuezva JM. Glucólisis y gluconeogénesis en el feto y neonato. En: Bioquímica Perinatal (Aspectos Básicos y Patológicos). Herrera, E. (ed.). Fundación Ramón Areces. Madrid, España. 1988; 227-252.

11. Medina J, Fernández E, Bolaños J, Vicario C, Arizmendi C. Fuel supply to the brain during the early postnatal period. In: Endocrine and biochemical development of the fetus and neonate. Cuezva, J. (ed.). Plenum Press. New York. 1996;175-194.

12. Yu A., Schousboe A, Hertz L. Metabolic fate of ${ }^{14} \mathrm{C}-$ labeled glutamate in astrocytes in primary culture. Journal of Neurochemistry. 1982; 39:954-960.

13. Yu A, Hertz L. Uptake of glutamate, GABA, and glutamine into a predominantly GABA-ergic and predominantly glutamatergic nerve cell population in culture. Journal of Neuroscience Research.1982; 7(1):23-35.

14. Tovar J, Salazar A. Compartimentación intracelular del acetato en astrocitos durante la prelactancia. Universitas Scientiarum. 2005; 10:39 - 50.

15. Albarracín $\mathrm{S}$, Tovar J. Metabolismo del $\left[\mathrm{U}-{ }^{14} \mathrm{C}\right]$-acetato $\mathrm{y}$ del $\left[2-{ }^{14} \mathrm{C}\right]$-acetato en astrocitos y astrocitoma $\mathrm{C}_{6}$. 2002; Biomédica. 22 (Suplemento 1):72.

16. Dierks-Ventling C. Prenatal induction of ketone body enzymes in the rat. Biology of the Neonate. 1971; 19:426-433. 
17. Cerdan S, Kunnecke B, Seelig J. Cerebral metabolism of $\left[1,2-{ }^{13} \mathrm{C}\right]$-acetate as detected by in vivo and in vitro ${ }^{13} \mathrm{C}$ NMR. Journal of Biological Chemistry. 1990; 265(22):12916-12926.

18. Hertz L. Astrocytic amino acid metabolism under control conditions and during oxygen and/or glucose deprivation. Neurochemical Research. 2003; 28(6): 941-953.

19. Bakken IJ, White LR, Aasly J, Unsgård G, Sonnewald U. $\left[\mathrm{U}-{ }^{13} \mathrm{C}\right]$-Aspartate metabolism in cultured cortical astrocytes and cerebellar granule neurons studied by NMR spectroscopy. Glia. 1998; 23(3):271-277.

20. Nicholls D, Attwell D. The release and uptake of exitatory amino acids. Trends in Pharmacological Sciences.1990; 11(11):462-468.

21. Danbolt N. The high-affinity uptake system for exitatory amino-acids in the brain. Progress in $\mathrm{Neu}$ robiology. 1994; 44:377-396.

22. Erecinska M. The neurotransmitter amino acids transport systems: A fresh outlook on an old problem. Biochemical Pharmacology. 1987; 36:3547-3555.

23. Gemba T, Oshima T, Ninomiya M. Glutamate efflux via the reversal of the sodium-dependent glutamate transporter caused by glycolytic inhibition in rat brain astrocytes. Neuroscience. 1994; 33:789-795.

24. Bernabé A, Méndez A, Hernández-Kelly C, Ortega A. Regulation of the $\mathrm{Na}^{+}$-dependent glutamate/aspartate transporter in rodent cerebellar astrocytes. Neurochemical Research. 2003; 28(12):1843-1849.

25. Sonnewald U, Wetergaard N, Petersen SB, Unsgard G, Schousboe A. Metabolism of $\left[\mathrm{U}-{ }^{13} \mathrm{C}\right]$-glutamate in astrocytes studied by ${ }^{13} \mathrm{C}$ NMR spectroscopy: incorporation of more label into lactate than into glutamine demostrates the importance of the tricarboxilic acid cycle. Journal of Neurochemistry. 1993; 61(3):11791182.

26. Bakken I, White L, Aasly J. Lactate formation from $\left[\mathrm{U}-{ }^{13} \mathrm{C}\right]$-aspartate in cultured astrocytes: compartmentation of pyruvate metabolism. Neuroscience Letters. 1997; 237(2):117-120.

27. Tsai G, Coyle J. N-acetylaspartate in neuropsychiatric disorders. Progress in Neurobiology.1995; 46(5):531-540.

28. Baslow M. A review of phylogenetic and metabolic relationships between the acylamino acids, $\mathrm{N}$-acetyl$\mathrm{L}$-aspartic and $\mathrm{N}$-acetyl-L-histidine, in the vertebrate nervous system. Journal of Neurochemistry. 1997; 68(4):1335-1344.

29. Tallan H. Studies on the distribution of N-acetyl-Laspartic acid in brain. The Journal of Biological Chemistry. 1957; 224:41-45.

30. Chakraborty G, Mekala P, Yahya D, Wu G, Ledeen RW. Intraneuronal N-acetylaspartate supplies acetyl groups for myelin lipids synthesis: evidence for myelin-associated aspartoacylase. Journal of Neurochemistry. 2001; 78(4):736-745.

31. Urenjak J, Williams S, Gadian D, Noble M. Specific expression of $\mathrm{N}$-acetylaspartate in neurons, oligondredocyte-type- 2 astrocite progenitors, and inmature oligodendrocytes in vitro. Journal of Neurochemistry. 1992; 59(1):55-61.

32. Taylor D, Davies SE, Obrenovitch TP; Urenjak J; Richards DA; Clark J B, Symon L. Extracellular Nacetylaspartate in the rat brain: in vivo determination of basal levels and changes evoked by high $\mathrm{K}^{+}$. Journal of Neurochemistry. 1994; 62(6): 2349-2355.

33. Sager T, Fink-Jensen A, Hansen A. Trasient elevation of interstitial $\mathrm{N}$-acetylaspartate in reversible global brain ischemia. Journal of Neurochemistry. 1997; 68(2):675-682.

34. Blakely R, Coyle J. The neurobiology of N-actylaspartylglutamate. International Review of Neurobiology. 1988; 30:39-100.

35. Taylor D, Davies S, Obrenovitch T, Doheny M, Patsalos P, Clark J, Symon, L. Investigation into the role of $\mathrm{N}$-acetylaspartate in cerebral osmo-regulation. Journal of Neurochemistry. 1995; 65(1):275-281.

36. Benuck M, D'Adamo A. Acetyl transport mechanisms. Metabolism of N.acetyl-L-aspartate acid in the nonnervous tissues of the rat. Biochimica et Biophysica Acta. 1968; 152:611-618.

37. Goldstein F. Amidohydrolases of brain, enzymatic hydrolysis of N-acetyl-L-aspartate and the other N-acylL-amino acids. Journal of Neurochemistry. 1976; 26(1):45-49.

38. Burri R, Steffen C, Herschkowitz N. N-acetyl-L-aspartate is a major source of acetyl groups for lipids synthesis during rat brain development. Developmental Neuroscience. 1991; 13:403-411.

39. Miller RH, David S, Patel R, Abney ER, Raff MC. A quantitative immunohistochemical study of macro- 
glial cell development in the rat optic nerve: in vivo evidence for two distinct astrocyte lineages. Developmental Biology. 1985; 111(1):35-41

40. Williams BP, Abney ER, Raff MC. 1985. Macroglial cell development in embrionic rat brain: studies using monoclonal antibodies, fluorescence activated cell sorting, and cell culture. Developmental Biology. 1985; 112:126-134.

41. Noble M. Points of controversy in the O-2A lineage clocks and type-2 astrocytes. Glia. 1991; 4(2):157164.

42. Oldendorf WH. Carrier-mediated blood-brain barrier transport of short-chain monocarboxylic organic acids. American Journal of Physiology. 1973; 224:14501453.

43. Cremer J, Braun L, Oldendorf W. Changes during development in transport processes of the blood-brain barrier. Biochimica et Biophysica Acta. 1976; 448:633-637.

44. Conn R, Fell D, Steele R. Characterizacion of a-keto acid transport across blood-brain barrier in rats. American Journal of Physiology. 1983; 245:E253-E260.

45. Sager T, Thomsen C, Valsborg J, Laursen H, Hansen A. Astroglia contain a specific transport mechanism for $\mathrm{N}$-acetyl-L-aspartate. Journal of Neurochemistry. 1999; 73:807-811.

46. Bender A, Dixon W, Steve W. The rapid L- and Daspartate uptake in cultured astrocytes. Neurochemical Research. 1997; 22(6):721-726.

47. Elliot K. The use of brain slices. In: Handbook of Neurochemistry. Laftha A. (ed.). New York, NY. Plenum Press. 1969; 2:103-115.

48. Sykes J, Lopez-Cardoso M, Van Den Bergh S. Substrate utilization for energy production and lipid synthesis in oligodendrocyte-enriched cultures prepared from rat brain. Neurochemistry International. 1986; 8:67-75.

49. Edmond J, Robbins RA, Bergstrom, JD, Cole RA, De Vellis J. Capacity for substrate utlization in oxidative metabolism by neurons astrocytes, and oligodendro- cytes from developing brain in primary culture. Journal of Neuroscience Research. 1987; 18(4):551-561.

50. Folch J, Lees M, Slone G. A simple method for the isolation and purification of total lipids from animal tissues. The Journal of Biological Chemistry. 1957; 226:497:599.

51. Tabernero A. 1993, Regulación del metabolismo del lactato en neuronas y astrocitos en cultivo primario. Tesis de maestría. Facultad de Farmacia. Departamento de Bioquímica y Biología Molecular. Universidad de Salamanca.186 p.

52. Bradford MM. A rapid and sensitive method for quantitation of microgram quantities of protein utilizing the principle of protein-dye binding. Analytical Biochemistry. 1976; 72:248-254.

53. Moffett JR, Ross B, Arun P, Madhavarao CN, Namboodiri AM. N-Acetylaspartate in the CNS: from neurodiagnostics to neurobiology. Progress in Neurobiology; 2007 81(2):89-131.

54. Baud O, Fayol L, Evrard P, Verney C. Movements of energy substrates in the mammalian brain, with special emphasis on transporters during normal and pathological development. Neuroembryology. 2002; 1:161-168

55. Liu Y, Yang CS, Tzeng S. Inhibitory regulation of glutamate aspartate transporter (GLAST) expression in astrocytes by cadmium-induced calcium influx. Journal of Neurochemistry. 2008; 105(1):137-150.

56. Bender AS, Woodbury DM, White HS. The rapid Land D-Aspartate uptake in cultured astrocytes. Neurochemical Research.1997; 22:721-726.

57. Rafalowska U., Erecinska M., Chance B..The effect of aspartate on citrate metabolism in the cytosolic fraction of brain under conditions of normoxia hypoxia and anaesthesia. Journal of Neurochemistry. 1975; 25:497-501.

58. Hertz L, Peng L, Dienel G. Energy metabolism in astrocytes: high rate of oxidative metabolism and spatiotemporal dependence on glycolysis/glycogenolysis. Journal. of Cerebral Blood Flow and Metabolism. 2007; 27(2):219-49. 